\title{
Apolipoprotein A1: a novel serum biomarker for predicting the prognosis of hepatocellular carcinoma after curative resection
}

\author{
Xiao-Lu Ma ${ }^{1, *}$, Xing-Hui Gao ${ }^{1, *}$, Zi-Jun Gong ${ }^{2, *}$, Jiong Wu ${ }^{1}$, Lu Tian ${ }^{1}$, Chun-Yan \\ Zhang ${ }^{1}$, Yan Zhou ${ }^{1}$, Yun-Fan Sun ${ }^{2}$, Bo Hu${ }^{2}$, Shuang-jian Qiu ${ }^{2}$, Jian Zhou ${ }^{2}$, Jia Fan ${ }^{2}$, \\ Wei Guo ${ }^{1}$, Xin-Rong Yang ${ }^{2}$ \\ ${ }^{1}$ Department of Laboratory Medicine, Zhongshan Hospital, Fudan University, Shanghai, P. R. China \\ ${ }^{2}$ Department of Liver Surgery, Liver Cancer Institute, Zhongshan hospital, Fudan University, Key Laboratory of Carcinogenesis \\ and Cancer Invasion, Ministry of Education, Shanghai, P. R. China \\ *These authors have contributed equally to this work \\ Correspondence to: Xin-Rong Yang, email: yang.xinrong@zs-hospital.sh.cn \\ Wei Guo, email: guo.wei@zs-hospital.sh.cn \\ Keywords: Apolipoprotein A 1, hepatocellular carcinoma, serum biomarker, prognosis, circulating tumor cell \\ Received: December 13,2015 Accepted: September 12, $2016 \quad$ Published: September 23, 2016
}

\section{ABSTRACT}

As a major protein constituent of high density lipoprotein, Apolipoprotein A1 (ApoA-1) might be associated with cancer progression. Our study investigated the serum ApoA-1 level for the prognosis of 443 patients with hepatocellular carcinoma (HCC) and its effects on tumor cells. We found that the serum ApoA-1 level was significantly lower in HCC patients with tumor recurrence, and was an independent indicator of tumor-free survival and overall survival. Low serum ApoA-1 levels were significantly associated with multiple tumors and high Barcelona Clinic Liver Cancer stage. The circulating tumor cell (CTC) levels were significantly higher in patients with low serum ApoA-1 compared with those with high serum ApoA-1 levels (4.03 \pm 0.98 vs. $1.48 \pm 0.22 ; p=0.001)$. In patients with detectable CTCs, those with low ApoA-1 levels had higher recurrence rates and shorter survival times. In vitro experiments showed that ApoA-1 can inhibit tumor cell proliferation through cell cycle arrest and promote apoptosis through down regulating mitogen-activated protein kinase (MAPK) pathway. In addition, ApoA-1 might impair extracellular matrix degradation properties of tumor cells. Taken together, our findings indicate that decreased serum ApoA-1 levels are a novel prognostic factor for HCC, and the role of ApoA-1 in inhibition of proliferation and promotion of apoptosis for tumor cells during their hematogenous dissemination are presumably responsible for the poor prognosis of patients with Iow ApoA-1 levels. Furthermore, AopA-1 might be a promising therapeutic target to reduce recurrence and metastasis for HCC patients after resection.

\section{INTRODUCTION}

Hepatocellular carcinoma (HCC) is the most prevalent malignant disease with the second highest mortality rate worldwide [1]. To date, surgery remains the most effective treatment for HCC; however, the prognosis of HCC remains unsatisfactory because of high recurrence and metastasis post-surgery $[2,3]$. The utility of conventional clinicopathological parameters, including histopathological characteristics, is insufficient for identifying patient subpopulations at high risk of recurrence and metastasis [4]. Therefore, there is an urgent requirement to develop novel biomarkers for identifying factors that predict tumor recurrence so that post-operative rational adjuvant treatments can be provided in a timely manner.

Apolipoprotein A1 (ApoA-1), which is encoded by a gene located on chromosome 11q23-q24, is a member of the apolipoprotein family $[5,6]$. As a major protein constituent of high density lipoprotein, ApoA-1 plays an important role in protecting against cardiovascular diseases because of its anti-atherogenic function [7-11]. Recent studies indicated that ApoA-1 could inhibit the formation of tumor vessels [12], induce an anti- 
tumor immune microenvironment that prevents tumor progression [13] and serve as a potential therapeutic target for patients with cancer [14-16]. A pilot study found that the serum ApoA-1 level was significantly lower in patients with $\mathrm{HCC}[17,18]$ and lower still in HCC patients with portal tumor thrombosis [19]. These findings implied that ApoA-1 might play a significant role in tumorigenesis and cancer progression of HCC. However, limited data were available on the clinical significance of serum ApoA-1 levels in HCC, and the mechanism of ApoA-1 involvement in HCC progression remained to be elucidated.

In this study, the serum ApoA-1 level was analyzed, and its clinical significance was evaluated in $433 \mathrm{HCC}$ patients from two independent cohorts. Furthermore, the correlation between the ApoA-1 level and the circulating tumor cell (CTC) level was explored, and the effect of ApoA-1 on HCC cell lines was investigated. We found that the serum ApoA-1 level was significantly higher in patients with non-recurrent HCC and correlated with improved survival. Furthermore, a significant negative correlation between serum ApoA-1 and CTC levels was observed, and ApoA-1 could significantly inhibit the proliferation and promote the apoptosis of HCC cells in vitro. The serum ApoA-1 level could therefore serve as a useful prognostic marker for HCC, potentially reflecting the survival of tumor cells during their hematogenous dissemination.

\section{RESULTS}

\section{Patient characteristics}

The clinicopathologic characteristics of patients with HCC are summarized in Table 1. In the training cohort, 109 of 224 patients suffered recurrence after resection with a median follow-up time of 28.7 months (range 0.6-37.0 months) and 59 of 224 patients died before the last follow-up (median follow-up 33.0 months, range 3.0-37.0 months). The validation cohort comprised 77 of 219 patients with $\mathrm{HCC}$ with confirmed recurrence with a median follow-up time of 20.3 months (range 1.0-30.0 months), and 171 patients were still alive at a median follow-up of 23.0 months (range 3.6-30.0 months). All clinical characteristics were similar between the training and validation cohorts (Table 1).

\section{Lower serum ApoA-1 level correlates with tumor recurrence and death of patients}

We investigated the correlation between serum ApoA-1 level, tumor recurrence, and death of patients in the training cohort. The serum ApoA-1 level was significantly lower in HCC patients with recurrent disease compared with patients without recurrence $(1.09 \pm 0.02 \mathrm{~g} / \mathrm{L}$ vs. $1.17 \pm 0.02 \mathrm{~g} / \mathrm{L}$, $p<0.05$, Figure 1A). Using the optimal cutoff value $(1.04 \mathrm{~g} / \mathrm{L}$, Supplementary Figure S1), a higher positive rate of patients with a low ApoA-1 level was observed in patients with tumor recurrence compared with patients without recurrence $(46.79 \%$ vs. $26.96 \%, p<0.05$, Figure 1A). Similarly, serum ApoA-1 level was significantly lower in patients who died $(1.08 \pm 0.03$ $\mathrm{g} / \mathrm{L} v s .1 .15 \pm 0.02 \mathrm{~g} / \mathrm{L}, p<0.05$, Supplementary Figure S2A) and the positive rate of low ApoA-1 levels was significantly higher in patients who died in the validation cohort $(47.46 \%$ vs. $32.73 \%, p<0.05$, Supplementary Figure S2B).

\section{Prognostic value of serum ApoA-1 levels in the training cohort}

Since the serum ApoA-1 level correlated with HCC recurrence and death, we further explored its prognostic significance in the training cohort. Using the X-tile 3.6.1 software, the optimal cutoff value $(1.04 \mathrm{~g} / \mathrm{L})$ was set as to stratify patients into low ApoA-1 $(\leq 1.04 \mathrm{~g} / \mathrm{L})$ and high $(>1.04$ $\mathrm{g} / \mathrm{L}$ ) groups (Supplementary Figure S1). Kaplan-Meier analysis showed that the time to recurrence (TTR) of HCC patients with a low serum ApoA-1 level was significantly shorter (median 17.1 months vs. not reached, $p=0.001$, Figure $1 \mathrm{~B}$ ) and had higher recurrence rates compared with those with a high ApoA-1 level (62.20\% vs. 40.85\%). Furthermore, the Overall survival (OS) of patients with $\mathrm{HCC}$ with a low serum ApoA-1 level was significantly shorter $(p=0.027$, Figure $1 \mathrm{~B})$ compared with those with a high ApoA-1 level (34.15\% vs. $21.83 \%$ ). In multivariate analysis, the serum ApoA-1 level was an independent indicator for TTR [Hazard ratio (HR), 0.39 ; 95\% confidence interval (CI): 0.26-0.60; $p<0.001$; Table 2] and OS (HR, 0.47; 95\% CI: 0.27-0.82; $p=0.008$; Table 2). The discrimination ability of ApoA-1 and clinical indices was compared by the area under curve (AUC) for TTR and OS (Figure 1C). The AUC for ApoA-1 was 0.60 (95\% CI, 0.530.63; Sensitivity, 0.468; Specificity, 0.630; Youden's index, 0.098 ) for TTR, and 0.57 (95\% CI, 0.49-0.66; Sensitivity, 0.475; Specificity, 0.673; Youden's index, 0.148) for OS, which was the strongest factor among indices (tumor number, tumor size, tumor encapsulation, tumor differentiation, vascular invasion, AFP, and BCLC stage) for predicting recurrence and survival in patients with HCC.

The prognostic significance of serum ApoA-1 level within conventional low-risk or $\alpha$-fetoprotein (AFP) $\leq 400$ $\mathrm{ng} / \mathrm{mL}$ subgroups was further investigated. We found that serum ApoA-1 level was significantly associated with TTR and $\mathrm{OS}$ for the variables as follows: AFP $\leq 400 \mathrm{ng} / \mathrm{mL}$ for TTR (median 13.4 months $v s$. not reached, $p=0.002$, Figure 2A), Barcelona Clinic Liver Cancer (BCLC) stages 0+A for TTR (median 13.5 months $v s$. not reached, $p<0.001$, Figure $2 \mathrm{~B}), \mathrm{AFP} \leq 400 \mathrm{ng} / \mathrm{mL}$ for $\mathrm{OS}(p=0.014$, Figure $2 \mathrm{C}$ ), BCLC $0+\mathrm{A}$ for $\mathrm{OS}(p=0.042$, Figure $2 \mathrm{D})$.

\section{Prognostic value of serum ApoA-1 level in the validation cohort}

The prognostic value of serum ApoA-1 level was further assessed using an independent cohort of 219 patients with HCC. The results were similar to those of 
Table 1: The clinicopathologic characteristics of patients in the training and validation cohorts

\begin{tabular}{|c|c|c|c|c|c|c|c|}
\hline \multirow[t]{2}{*}{ Characteristics } & & \multirow[t]{2}{*}{ No. of patients } & \multicolumn{2}{|c|}{ Training cohort } & \multicolumn{2}{|c|}{ Validation cohort } & \multirow[t]{2}{*}{$P$} \\
\hline & & & $N=224$ & $\%$ & $\mathrm{~N}=\mathbf{2 1 9}$ & $\%$ & \\
\hline \multirow[t]{2}{*}{ Age (years) } & $\leq 50$ & 172 & 85 & 37.95 & 87 & 39.73 & 0.770 \\
\hline & $>50$ & 271 & 139 & 62.05 & 132 & 60.27 & \\
\hline \multirow[t]{2}{*}{ Sex } & Women & 73 & 33 & 14.73 & 40 & 18.26 & 0.370 \\
\hline & Men & 370 & 191 & 85.27 & 179 & 81.74 & \\
\hline \multirow[t]{2}{*}{$\mathrm{AFP}, \mathrm{ng} / \mathrm{mL}$} & $\leq 400$ & 311 & 157 & 70.09 & 154 & 70.32 & 1.000 \\
\hline & $>400$ & 132 & 67 & 29.91 & 65 & 29.68 & \\
\hline \multirow[t]{2}{*}{ ALT, U/L } & $\leq 75$ & 412 & 211 & 94.20 & 201 & 91.78 & 0.355 \\
\hline & $>75$ & 31 & 13 & 5.80 & 18 & 8.22 & \\
\hline \multirow[t]{2}{*}{$\gamma-\mathrm{GT}, \mathrm{U} / \mathrm{L}$} & $\leq 54$ & 258 & 131 & 58.48 & 127 & 58.00 & 0.924 \\
\hline & $>54$ & 185 & 93 & 41.52 & 92 & 42.00 & \\
\hline \multirow[t]{2}{*}{ HBsAg } & Negative & 58 & 28 & 12.50 & 30 & 13.70 & 0.779 \\
\hline & Positive & 385 & 196 & 87.50 & 189 & 86.30 & \\
\hline \multirow[t]{2}{*}{ Liver cirrhosis } & No & 108 & 51 & 22.77 & 57 & 26.03 & 0.440 \\
\hline & Yes & 335 & 173 & 77.23 & 162 & 73.97 & \\
\hline \multirow[t]{2}{*}{ No. of tumors } & Single & 362 & 180 & 80.36 & 182 & 83.11 & 0.464 \\
\hline & Multiple & 81 & 44 & 19.64 & 37 & 16.89 & \\
\hline \multirow[t]{2}{*}{ Tumor size, $\mathrm{cm}$} & $\leq 5$ & 272 & 141 & 62.95 & 131 & 59.82 & 0.558 \\
\hline & $>5$ & 171 & 83 & 37.05 & 88 & 40.18 & \\
\hline \multirow[t]{2}{*}{ Tumor encapsulation } & Complete & 285 & 140 & 62.50 & 145 & 66.21 & 0.429 \\
\hline & None & 158 & 84 & 37.50 & 74 & 33.79 & \\
\hline \multirow[t]{2}{*}{ Satellite lesion } & No & 398 & 199 & 88.84 & 199 & 90.87 & 0.531 \\
\hline & Yes & 45 & 25 & 11.16 & 20 & 9.13 & \\
\hline \multirow[t]{2}{*}{ Vascular invasion } & No & 262 & 137 & 61.16 & 125 & 57.08 & 0.386 \\
\hline & Yes & 181 & 87 & 38.84 & 94 & 42.92 & \\
\hline \multirow[t]{2}{*}{$\begin{array}{l}\text { Tumor } \\
\text { differentiation }\end{array}$} & I-II & 283 & 142 & 63.39 & 141 & 64.38 & 0.844 \\
\hline & III-IV & 160 & 82 & 36.61 & 78 & 35.62 & \\
\hline \multirow[t]{2}{*}{ Child-Pugh score } & A & 409 & 210 & 93.75 & 199 & 90.87 & 0.287 \\
\hline & $\mathrm{B}$ & 34 & 14 & 6.25 & 20 & 9.13 & \\
\hline \multirow[t]{2}{*}{ BCLC stage } & $0+\mathrm{A}$ & 329 & 166 & 74.11 & 163 & 74.43 & 1.000 \\
\hline & $\mathrm{B}+\mathrm{C}$ & 114 & 58 & 25.89 & 56 & 25.57 & \\
\hline
\end{tabular}

Abbreviations: AFP, $\alpha$-fetoprotein; ALT, alanine aminotransferase; $\gamma$-GT, $\gamma$-Glutamyltransferase; HBsAg, hepatitis B surface antigen; BCLC, Barcelona Clinic Liver Cancer.

the training cohort (Figure 1). A low serum ApoA-1 level was associated with shorter TTR (median 20.0 months vs. not reached, $p=0.001$, Figure $1 \mathrm{E})$ and $\mathrm{OS}(p=0.003$, Figure 1E). Cox regression analyses demonstrate that the serum ApoA-1 level was an independent indicator of TTR (HR, $0.53 ; 95 \%$ CI, 0.33-0.87; $p=0.011$; Table 2) and OS (HR, 0.44; 95\% CI, 0.24-0.77; $p=0.010$; Table 2). Moreover, similar to the training cohort, the prognostic significance of the serum ApoA-1 level remained in the low-risk and AFP $\leq 400 \mathrm{ng} / \mathrm{mL}$ subgroups (all $p<0.05$ ) (Figure 2). The discrimination ability of ApoA-1, as assessed by AUC, was 0.59 (95\%CI, 0.53-0.62; 
Sensitivity, 0.364; Specificity, 0.810; Youden's index, 0.174 ) and 0.61 (95\% CI, 0.54-0.66; Sensitivity, 0.417; Specificity, 0.795; Youden's index, 0.212) for TTR and OS (Figure 1F) respectively, which was higher than other clinical indexes.

\section{Correlation between the serum ApoA-1 level and clinical characteristics}

Patients with HCC and a low serum ApoA-1 level were more likely to have multiple tumors $(p=0.023$, Table 3) and a high BCLC stage $(p=0.007$, Table 3$)$ compared with those with a high serum ApoA-1 level. There was no significant difference in other clinical characteristics, including tumor size and vascular invasion (either micro or major) between the high and low serum ApoA-1-level groups in the training cohort. In the validation cohort, a low serum ApoA-1 level was associated with a high AFP level $(p=0.001$, Table 3$)$ and a greater proportion of men $(p=0.045$, Table 3$)$.

\section{Correlation between the serum ApoA-1 level and CTC and its prognostic significance in $\mathrm{HCC}$ patients with detectable CTC}

The correlation between serum ApoA-1 and CTC levels was further investigated. Scatter-plot analyses revealed a significant negative correlation between serum ApoA-1 and CTC levels ( $\mathrm{r}=-0.235 ; p=0.013$; Figure $3 \mathrm{~A})$. The levels of CTC were significantly higher in patients with a low ApoA-1 level compared with those with a high serum ApoA-1 level (4.03 \pm 0.98 vs. $1.48 \pm 0.22 ; p=0.001$; Figure $3 \mathrm{~B}$ ).

In light of the close relationship between CTC and serum ApoA-1 levels, we further explored the prognostic significance of serum ApoA-1 level in subgroups of patients presenting with CTC. In patients with detectable CTC, ApoA-1 levels $\leq 1.04 \mathrm{~g} / \mathrm{L}$ were associated with higher recurrence rates $(70.0 \%$ vs. $37.2 \% ; p<0.05)$ and a shorter TTR (median, 7.6 months vs. not reached; $p=0.017$ ) compared with patients with ApoA-1 > $1.04 \mathrm{~g} / \mathrm{L}$
A

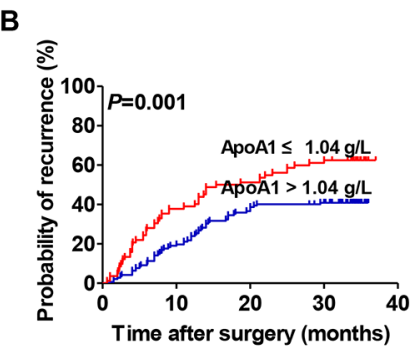

C

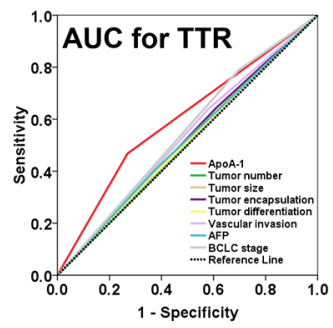

Training cohort
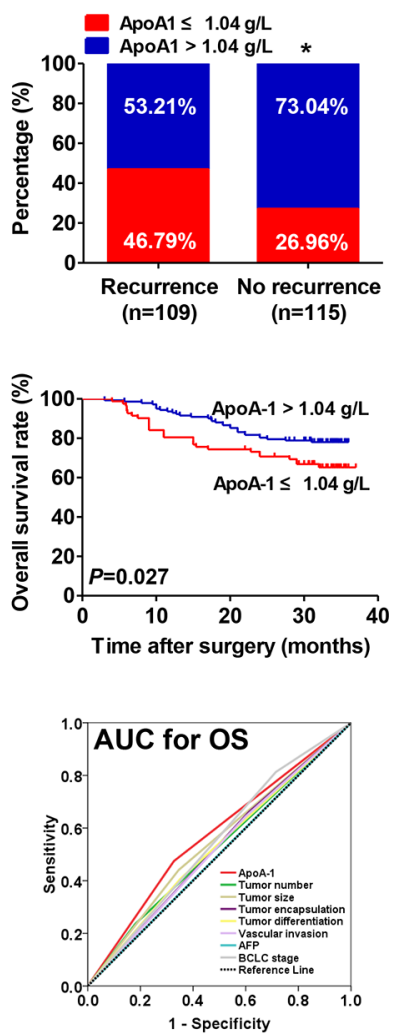

D

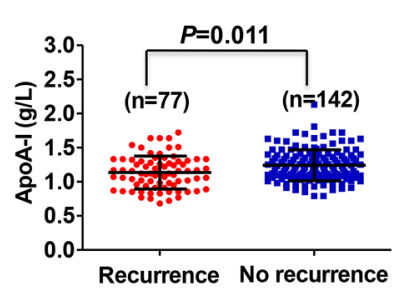

E

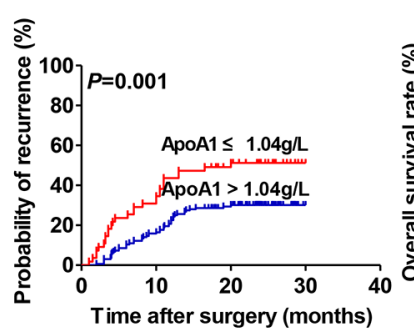

$\mathbf{F}$

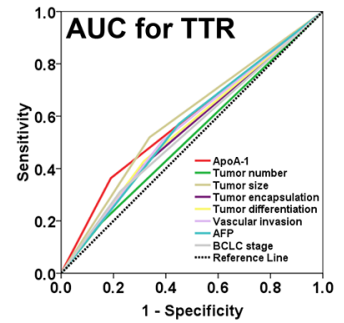

Validation cohort
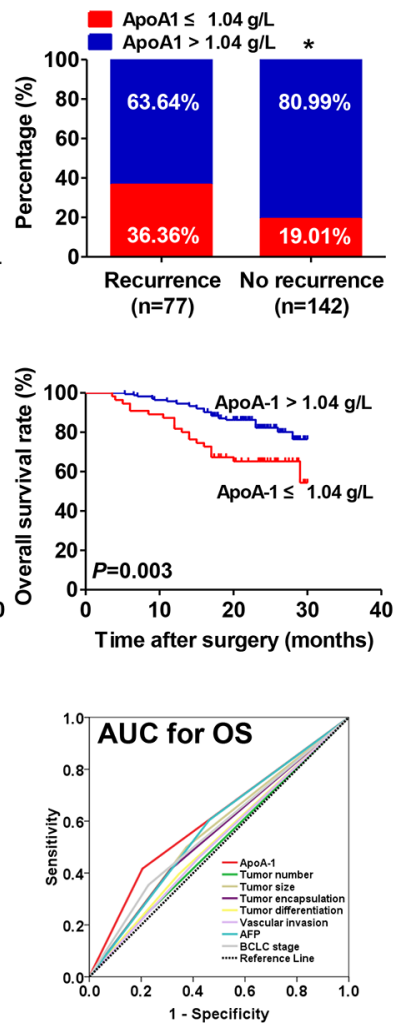

Figure 1: Prognostic significance of serum ApoA-1 levels in HCC patients underwent curative resection. A. Distribution of serum ApoA-1 levels (left) and ApoA-1-positive rate (right) in recurrent and non-recurrent patients from the training cohort. B. Kaplan-Meier analysis for TTR (left) and OS (right) of patients with HCC according to serum ApoA-1 level in the training cohort. C. TTR (left) and OS (right) predictive ability of ApoA-1 was compared with other clinical parameters by ROC curves in the training cohort. D. Distribution of serum ApoA-1 levels (left) and ApoA-1-positive rate (right) in recurrent and non-recurrent patients from the validation cohort. E. Kaplan-Meier analysis for TTR (left) and OS (right) of patients with HCC according to serum ApoA-1 level in the validation cohort. F. TTR (left) and OS (right) predictive ability of ApoA-1 was compared with other clinical parameters by ROC curves in the validation cohort. “*” indicated $P<0.05$. 
Table 2: Multivariate Cox regression analyses in the training and validation cohort

\begin{tabular}{|c|c|c|c|c|}
\hline \multirow[t]{2}{*}{ Variables } & \multicolumn{2}{|c|}{ TTR } & \multicolumn{2}{|c|}{ OS } \\
\hline & HR(95\% CI) & $\boldsymbol{P}$ & HR(95\% CI) & $\boldsymbol{P}$ \\
\hline \multicolumn{5}{|l|}{ Training cohort } \\
\hline AFP, $\mathrm{ng} / \mathrm{ml}(>400$ vs $\leq 400)$ & $1.048(0.681-1.641)$ & 0.832 & $0.548(0.282-1.068)$ & 0.077 \\
\hline$\gamma-\mathrm{GT}, \mathrm{U} / \mathrm{L}(>54$ vs $\leq 54)$ & $2.488(1.654-3.743)$ & $<0.001$ & $1.930(1.117-3.332)$ & 0.018 \\
\hline No. of tumors, (multiple vs single) & $0.856(0.508-1.443)$ & 0.559 & $1.065(0.547-2.076)$ & 0.852 \\
\hline Tumor size, $\mathrm{cm}(>5$ vs $\leq 5)$ & $0.861(0.553-1.340)$ & 0.507 & $1.483(0.838-2.625)$ & 0.176 \\
\hline $\begin{array}{l}\text { Tumor encapsulation, (none vs } \\
\text { complete) }\end{array}$ & $1.250(0.833-1.875)$ & 0.281 & $1.196(0.690-2.074)$ & 0.524 \\
\hline Satellite lesion, (yse vs no) & $0.907(0.484-1.700)$ & 0.761 & $0.776(0.330-1.827)$ & 0.562 \\
\hline Vascular invasion, (yes vs no) & $0.735(0.474-1.139)$ & 0.169 & $0.707(0.392-1.275)$ & 0.249 \\
\hline $\begin{array}{l}\text { Tumor differentation, (III-IV VS } \\
\text { I-II) }\end{array}$ & $1.014(0.662-1.552)$ & 0.950 & $1.102(0.623-1.950)$ & 0.738 \\
\hline ApoA-1, g/L ( >1.04 vs $\leq 1.04)$ & $0.394(0.260-0.598)$ & $<0.001$ & $0.474(0.273-0.824)$ & 0.008 \\
\hline \multicolumn{5}{|l|}{ Validation cohort } \\
\hline AFP, $\mathrm{ng} / \mathrm{ml}(>400$ vs $\leq 400)$ & $1.205(0.717-2.024)$ & 0.481 & $1.199(0.623-2.307)$ & 0.588 \\
\hline$\gamma-\mathrm{GT}, \mathrm{U} / \mathrm{L}(>54$ vs $\leq 54)$ & $1.158(0.731-1.834)$ & 0.532 & $1.484(0.821-2.685)$ & 0.191 \\
\hline No. of tumors, (multiple vs single) & $1.041(0.576-1.881)$ & 0.895 & $0.923(0.427-1.994)$ & 0.837 \\
\hline Tumor size, $\mathrm{cm}(>5$ vs $\leq 5)$ & $1.640(0.974-2.760)$ & 0.063 & $1.537(0.796-2.969)$ & 0.200 \\
\hline $\begin{array}{l}\text { Tumor encapsulation, (none vs } \\
\text { complete) }\end{array}$ & $0.782(0.485-1.261)$ & 0.313 & $0.678(0.371-1.238)$ & 0.206 \\
\hline Satellite lesion, (yse vs no) & $1.183(0.581-2.411)$ & 0.643 & $1.159(0.464-2.894)$ & 0.751 \\
\hline Vascular invasion, (yes vs no) & $0.971(0.577-1.636)$ & 0.913 & $0.828(0.427-1.604)$ & 0.575 \\
\hline $\begin{array}{l}\text { Tumor differentation, (III-IV VS } \\
\text { I-II) }\end{array}$ & $1.204(0.743-1.953)$ & 0.451 & $0.948(0.508-1.769)$ & 0.867 \\
\hline ApoA-1, g/L (>1.04 vs $\leq 1.04)$ & $0.532(0.326-0.868)$ & 0.011 & $0.444(0.243-0.772)$ & 0.010 \\
\hline
\end{tabular}

Abbreviations: AFP, $\alpha$-fetoprotein; $\gamma$-GT, $\gamma$-Glutamyltransferase; ApoA-1, Apolipoprotein A1; TTR, time to recurrence; OS, Overall survival; HR, hazard ratio; CI, confidence interval.

(Figure 3C). In terms of OS, we also found that overall survival rate was significantly lower in patients with low ApoA-1 levels than those with high ApoA-1 levels $(p=0.020$, Figure $3 \mathrm{C})$.

\section{ApoA-1 inhibits tumor cell proliferation, induces apoptosis and impairs their extracellular matrix degradation properties}

To explore the effect of ApoA-1 on tumor cells, cell proliferation was analyzed. Compared with negative control (i.e., tumor cells treated without ApoA-1), tumor cell viability with ApoA-1 was significantly suppressed in a time-dependent manner after exposure to 25 or $50 \mu \mathrm{g} /$ $\mathrm{mL}$ ApoA-1 for 7 days $(0.834 \pm 0.004$ vs. $1.142 \pm 0.042$ for 5 days in $\mathrm{MHCC} 97 \mathrm{H}, p<0.05 ; 0.870 \pm 0.008$ vs. 1.098 \pm 0.012 for 5 days in Huh7, $p<0.05$, Figure 3D). Further cell cycle tests were performed on MHCC97H cells and results showed that the percentage of cells in $\mathrm{G}_{0 /} \mathrm{G}_{1}$ phase increased while the percentage of cells in $S$ and $G_{2} / M$ phase decreased after ApoA-1 treatment (Figure 3E), which indicated cell cycle blocking function of ApoA-1.

The effect of ApoA-1 on tumor cell apoptosis was also investigated. We found that ApoA-1 treatmentinduced apoptosis rates were $30.06 \pm 1.51 \%$ and $21.67 \pm$ $1.25 \%$ in MHCC97H and Huh7 cells, while the apoptosis rates were $12.34 \pm 1.21 \%$ and $15.17 \pm 1.18 \%$ in those without ApoA-1 treatment ( $p<0.001$, Figure 4A).

Furthermore, we performed RT-PCR to observe expression changes of several invasion-related genes. Results showed that expression of epithelial-mesenchymal transition-related (EMT-related) genes showed no difference before and after ApoA-1 treatment. However, matrix metalloproteinases (MMPs) including MMP-2 


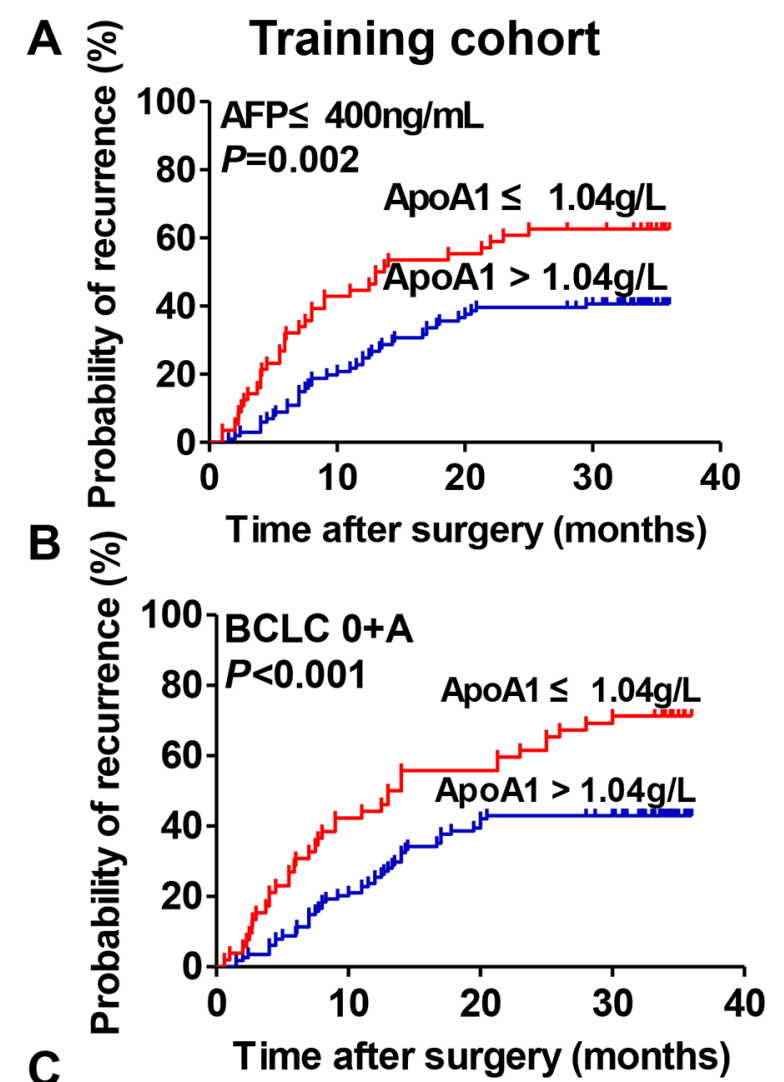

C
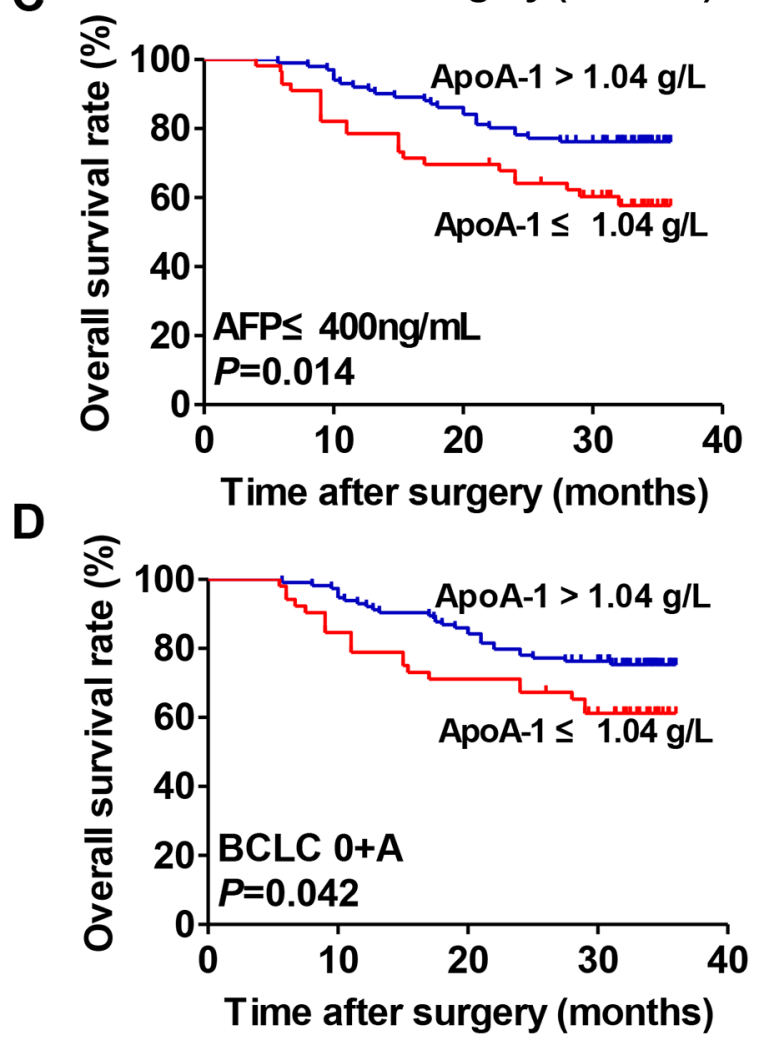
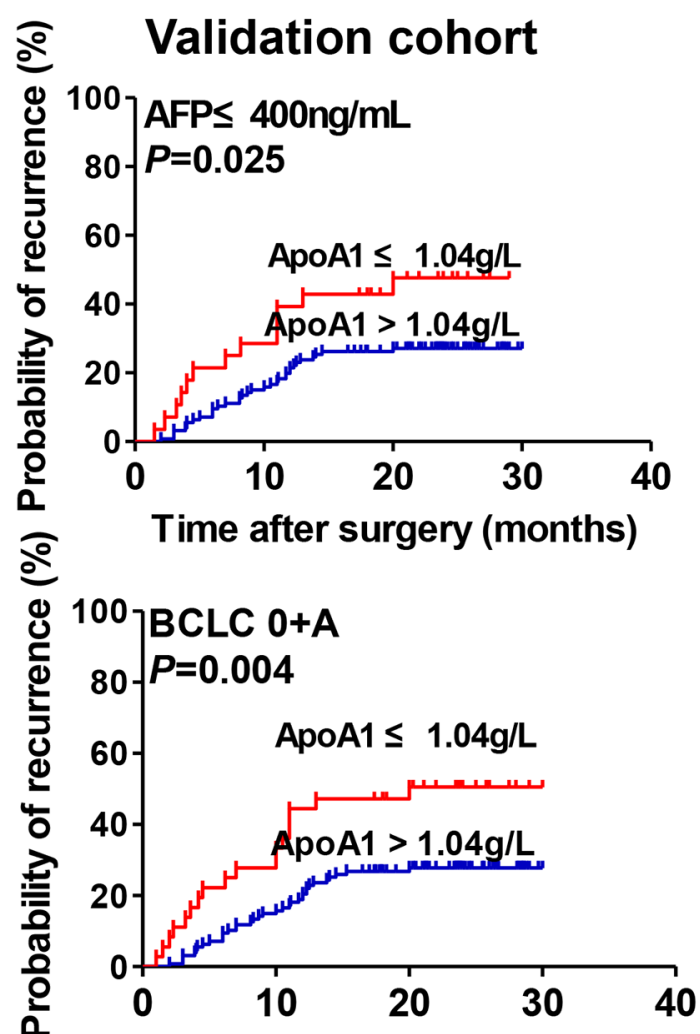

Time after surgery (months)

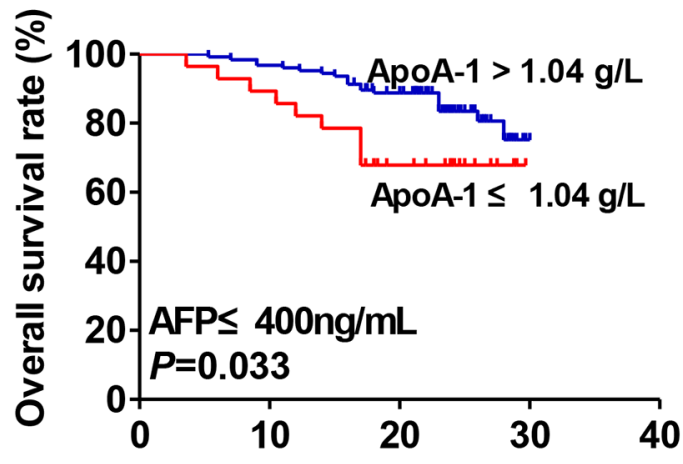

Time after surgery (months)

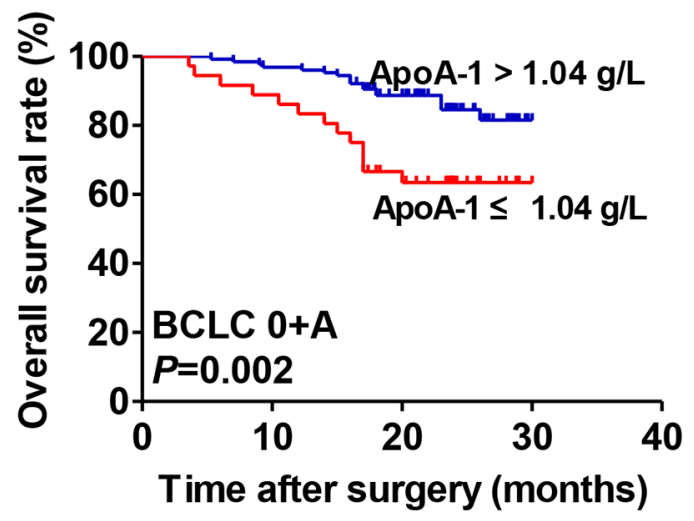

Figure 2: Prognostic significance of serum ApoA-1 levels of HCC patients in the low-risk and AFP $\leq 400 \mathrm{ng} / \mathrm{mL}$ subgroups. A. Kaplan-Meier analysis of TTR of patients with $\mathrm{HCC}$ with AFP $\leq 400 \mathrm{ng} / \mathrm{mL}$ in the training (left) and validation (right) cohorts. B. Kaplan-Meier analysis of TTR of patients with HCC with BCLC stage 0+A in the training (left) and validation (right) cohorts. C. Kaplan-Meier analysis of OS of patients with HCC with AFP $\leq 400 \mathrm{ng} / \mathrm{mL}$ in training (left) and validation (right) cohorts. D. KaplanMeier analysis of OS of patients with HCC with BCLC stage 0+A in training (left) and validation (right) cohorts. 
Table 3: Correlation between serum ApoA-1 levels and clinicopathologic characteristics

\begin{tabular}{|c|c|c|c|c|c|c|c|}
\hline \multirow{2}{*}{$\begin{array}{l}\text { Clinical } \\
\text { characteristics }\end{array}$} & & \multicolumn{3}{|c|}{ Training cohort } & \multicolumn{3}{|c|}{ Validation cohort } \\
\hline & & $\begin{array}{c}\text { ApoA-1 } \\
\leq 1.04 \mathrm{~g} / \mathrm{L} \\
(\mathrm{N}=82)\end{array}$ & $\begin{array}{c}\text { ApoA-1 } \\
>1.04 \mathrm{~g} / \mathrm{L} \\
(\mathrm{N}=142)\end{array}$ & $P$ & $\begin{array}{c}\text { ApoA-1 } \\
\leq 1.04 \mathrm{~g} / \mathrm{L} \\
(\mathrm{N}=55)\end{array}$ & $\begin{array}{c}\text { ApoA-1 } \\
>1.04 g / L \\
(\mathrm{~N}=164)\end{array}$ & $P$ \\
\hline \multirow[t]{2}{*}{ Age } & $\leq 50$ & 32 & 53 & 0.886 & 20 & 67 & 0.634 \\
\hline & $>50$ & 50 & 89 & & 35 & 97 & \\
\hline \multirow[t]{2}{*}{ Sex } & Female & 9 & 24 & 0.248 & 5 & 35 & $0.045^{\mathrm{a}}$ \\
\hline & Male & 73 & 118 & & 50 & 129 & \\
\hline \multirow[t]{2}{*}{ AFP, $n g / m L$} & $\leq 400$ & 56 & 101 & 0.653 & 28 & 126 & 0.001 \\
\hline & $>400$ & 26 & 41 & & 27 & 38 & \\
\hline \multirow[t]{2}{*}{ ALT, U/L } & $\leq 75$ & 78 & 133 & $0.773^{\mathrm{a}}$ & 50 & 151 & $0.780^{\mathrm{a}}$ \\
\hline & $>75$ & 4 & 9 & & 5 & 13 & \\
\hline \multirow[t]{2}{*}{$\gamma-\mathrm{GT}, \mathrm{U} / \mathrm{L}$} & $\leq 54$ & 55 & 76 & 0.050 & 35 & 92 & 0.348 \\
\hline & $>54$ & 27 & 66 & & 20 & 72 & \\
\hline \multirow[t]{2}{*}{ HBsAg } & Negative & 10 & 18 & 1.000 & 11 & 19 & 0.120 \\
\hline & Positive & 72 & 124 & & 44 & 145 & \\
\hline \multirow[t]{2}{*}{ Liver cirrhosis } & No & 20 & 31 & 0.741 & 16 & 41 & 0.595 \\
\hline & Yes & 62 & 111 & & 39 & 123 & \\
\hline \multirow[t]{2}{*}{ No. of tumor } & Single & 59 & 121 & 0.023 & 43 & 139 & 0.299 \\
\hline & Multiple & 23 & 21 & & 12 & 25 & \\
\hline \multirow[t]{2}{*}{ Tumor size, cm } & $\leq 5$ & 48 & 93 & 0.317 & 27 & 104 & 0.080 \\
\hline & $>5$ & 34 & 48 & & 28 & 60 & \\
\hline \multirow[t]{2}{*}{$\begin{array}{l}\text { Tumor } \\
\text { encapsulation }\end{array}$} & Complete & 47 & 93 & 0.253 & 34 & 111 & 0.510 \\
\hline & None & 35 & 49 & & 21 & 53 & \\
\hline \multirow[t]{2}{*}{ Satellite lesion } & No & 70 & 129 & 0.271 & 49 & 150 & 0.594 \\
\hline & Yes & 12 & 13 & & 6 & 14 & \\
\hline \multirow[t]{2}{*}{ Vascular invasion } & No & 46 & 91 & 0.257 & 27 & 98 & 0.208 \\
\hline & Yes & 36 & 51 & & 28 & 66 & \\
\hline \multirow[t]{2}{*}{$\begin{array}{l}\text { Tumor } \\
\text { differentation }\end{array}$} & I-II & 47 & 95 & 0.195 & 30 & 111 & 0.103 \\
\hline & III-IV & 35 & 47 & & 25 & 53 & \\
\hline \multirow[t]{2}{*}{ Child-Pugh score } & A & 76 & 134 & 0.775 & 50 & 149 & $1.000^{\mathrm{a}}$ \\
\hline & B & 6 & 8 & & 5 & 15 & \\
\hline \multirow[t]{2}{*}{ BCLC stage } & $0+\mathrm{A}$ & 52 & 114 & 0.007 & 36 & 127 & 0.107 \\
\hline & $\mathrm{B}+\mathrm{C}$ & 30 & 28 & & 19 & 37 & \\
\hline
\end{tabular}

Abbreviations: AFP, $\alpha$-fetoprotein; ALT, alanine aminotransferase; $\gamma$-GT, $\gamma$-Glutamyltransferase; HBsAg, hepatitis B surface antigen; BCLC, Barcelona Clinic Liver Cancer; ApoA-1, Apolipoprotein A1.

${ }^{a}$ Fisher exact test. 
A

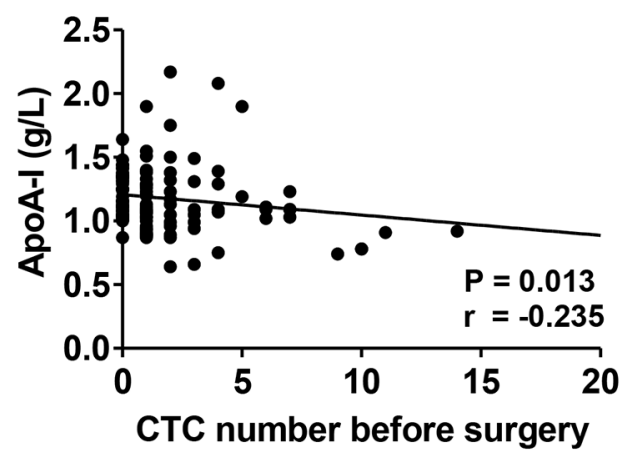

C

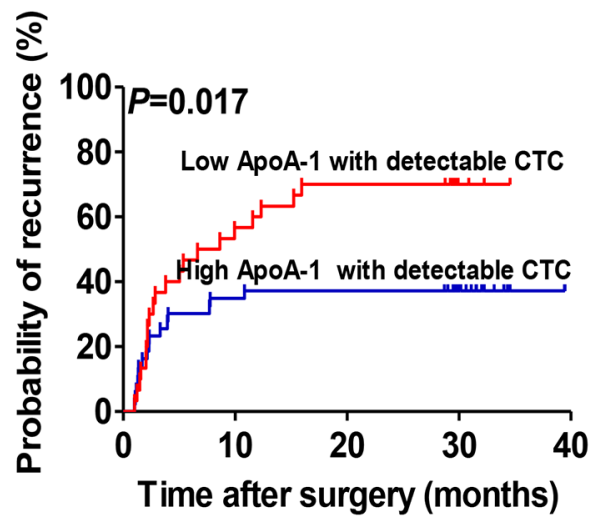

D

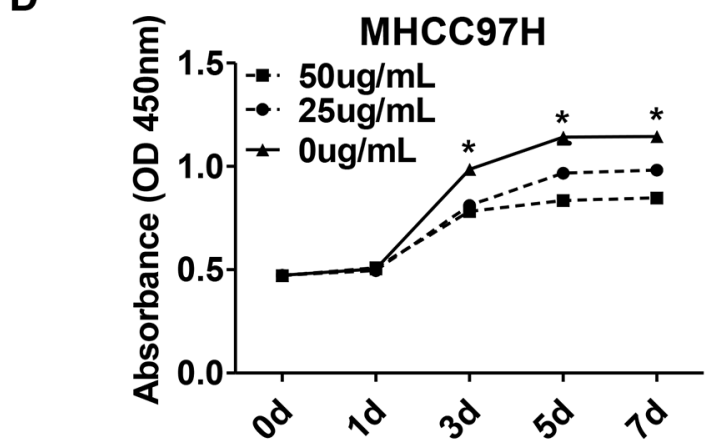

B

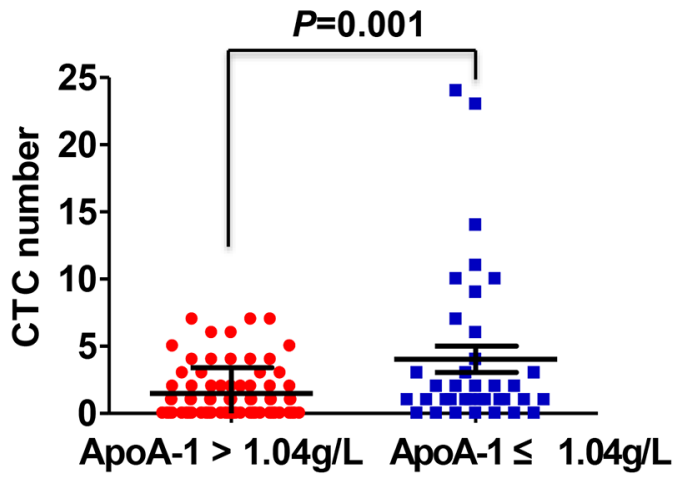

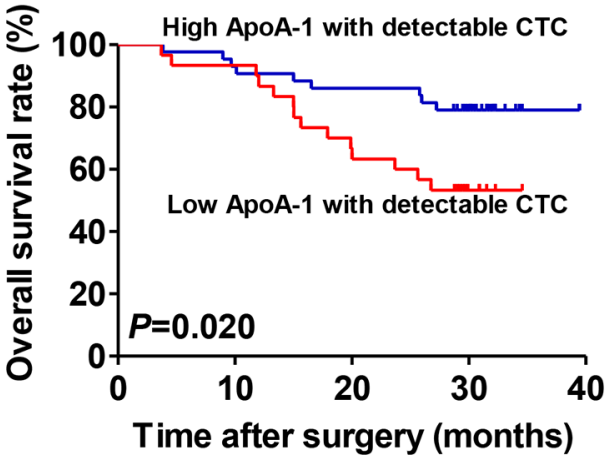

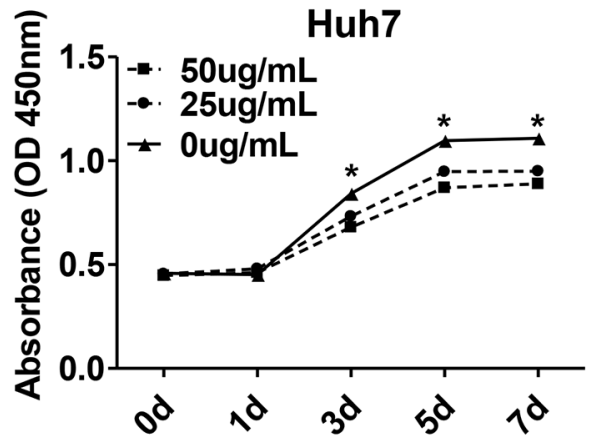

$\mathbf{E}$
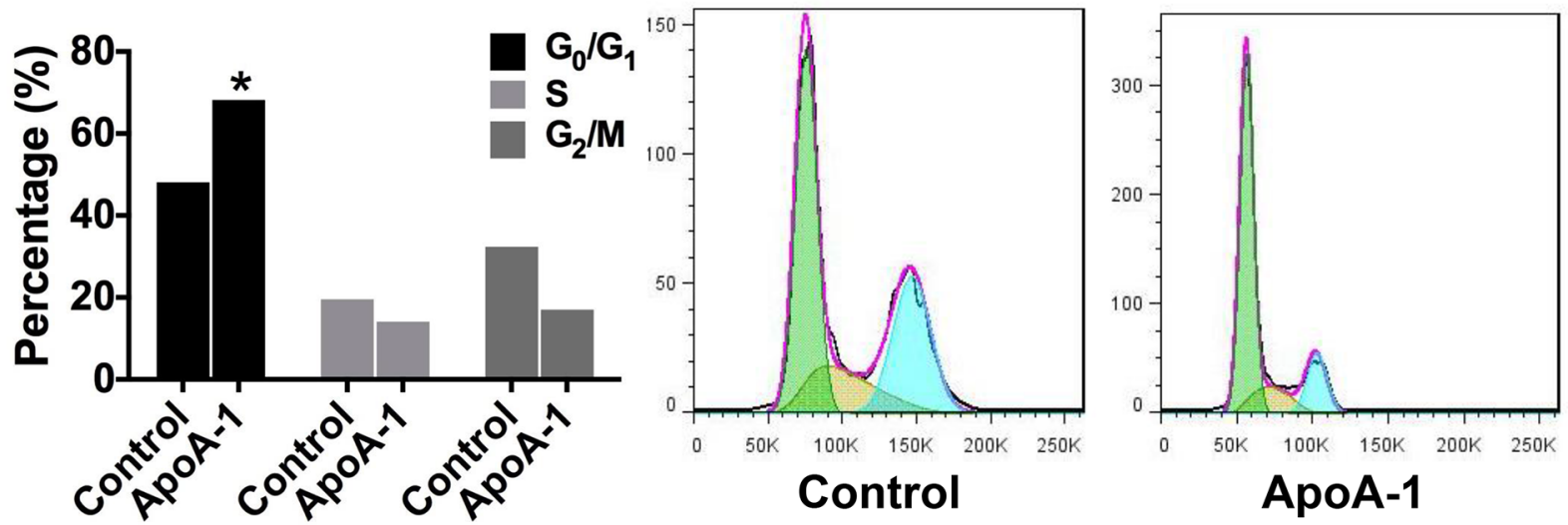

Figure 3: Correlation between serum ApoA-1 levels and CTC. A. Correlation between serum ApoA-1 levels and the number of CTCs. B. CTC-positive rates of HCC patients with different serum ApoA-1 levels. C. The Kaplan-Meier analysis of TTR (left) and OS (right) for serum ApoA-1 levels in patients with detectable CTC. D. Cell viability was significantly inhibited by $25 \mathrm{or} 50 \mathrm{ug} / \mathrm{mL}$ ApoA-1 compared with control group in MHCC97H (left) and Huh7 (right) cell lines. E. ApoA-1 treatment could effectively result in G0/G1 arrest in MHCC97H. “*” indicated $P<0.05$. 
and MMP-9 showed significant decrease after ApoA-1 treatment in both two cell lines, which indicating ApoA-1 might inhibit CTC formation via impairing extracellular matrix degradation properties of tumor cells. In addition, we also observed a dramatic decrease of vascular endothelial growth factor (VEGF) mRNA, which was in accordance with a previous study [12] (Figure 4B).

\section{ApoA-1-induced apoptosis was associated with mitogen-activated protein kinase (MAPK) pathway}

Next, to further address how ApoA-1 induced apoptosis in HCC cells, a human apoptosis PCR-array was used to determine the expression of apoptosis -regulatory genes in Huh7 cells. A total of 88 genes were tested for screening potential pathway, For the sake of reliability, 74 genes with a $\mathrm{Cq}$ value less than 35 were further selected for comparison. When 1.50 was set as the cutoff for changes of expression (ApoA-1 treated versus untreated), the expressions of 14 genes were significantly altered by ApoA-1 treatment. Among these 14 genes, the expression of three pro-apoptotic genes including caspase 5 (CASP5), tumor necrosis factor receptor superfamily member $10 \mathrm{~B}$ (TNFRSF10B), and apoptotic protease activating factor-1 (AFAP-1) were up-regulated (fold change: 1.62, 1.53, and 1.52, respectively). Meanwhile, the expressions of 11 anti-apoptotic genes including MAPK1 (also known as ERK2), MAPK3 (also known as ERK1), and Inhibitor of
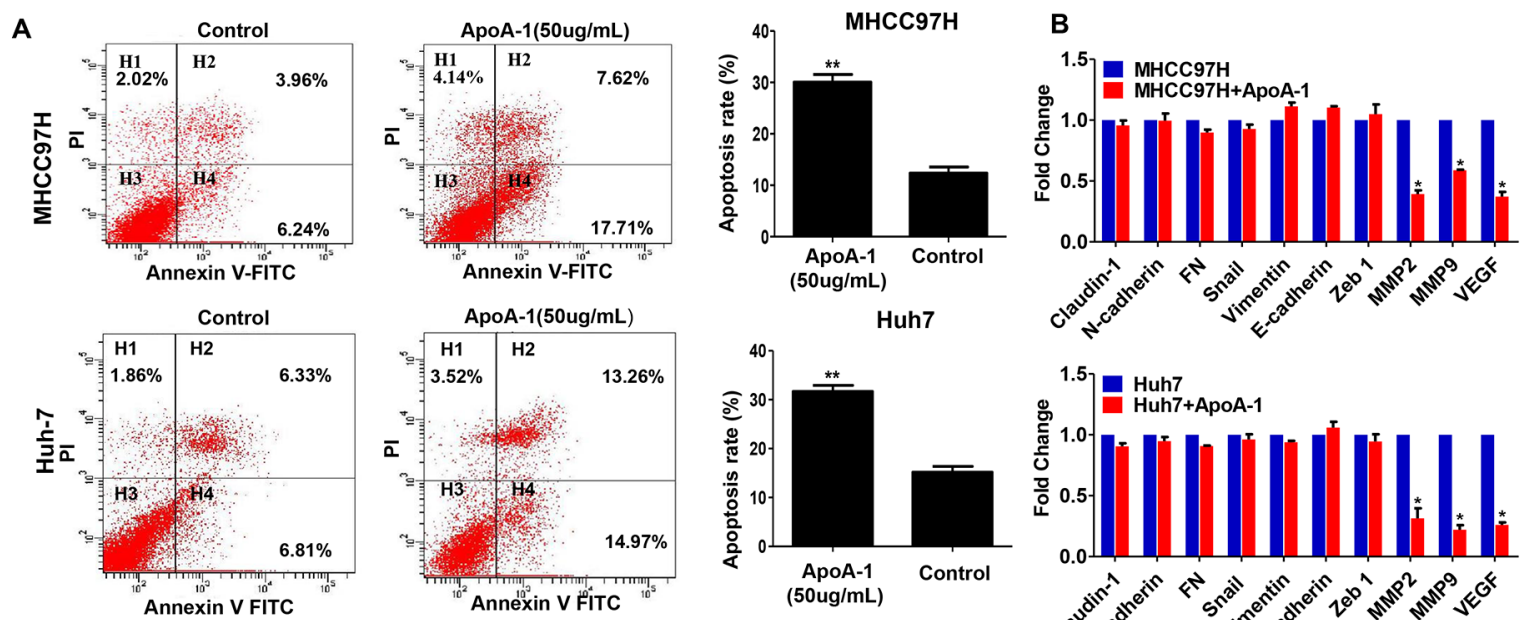

C
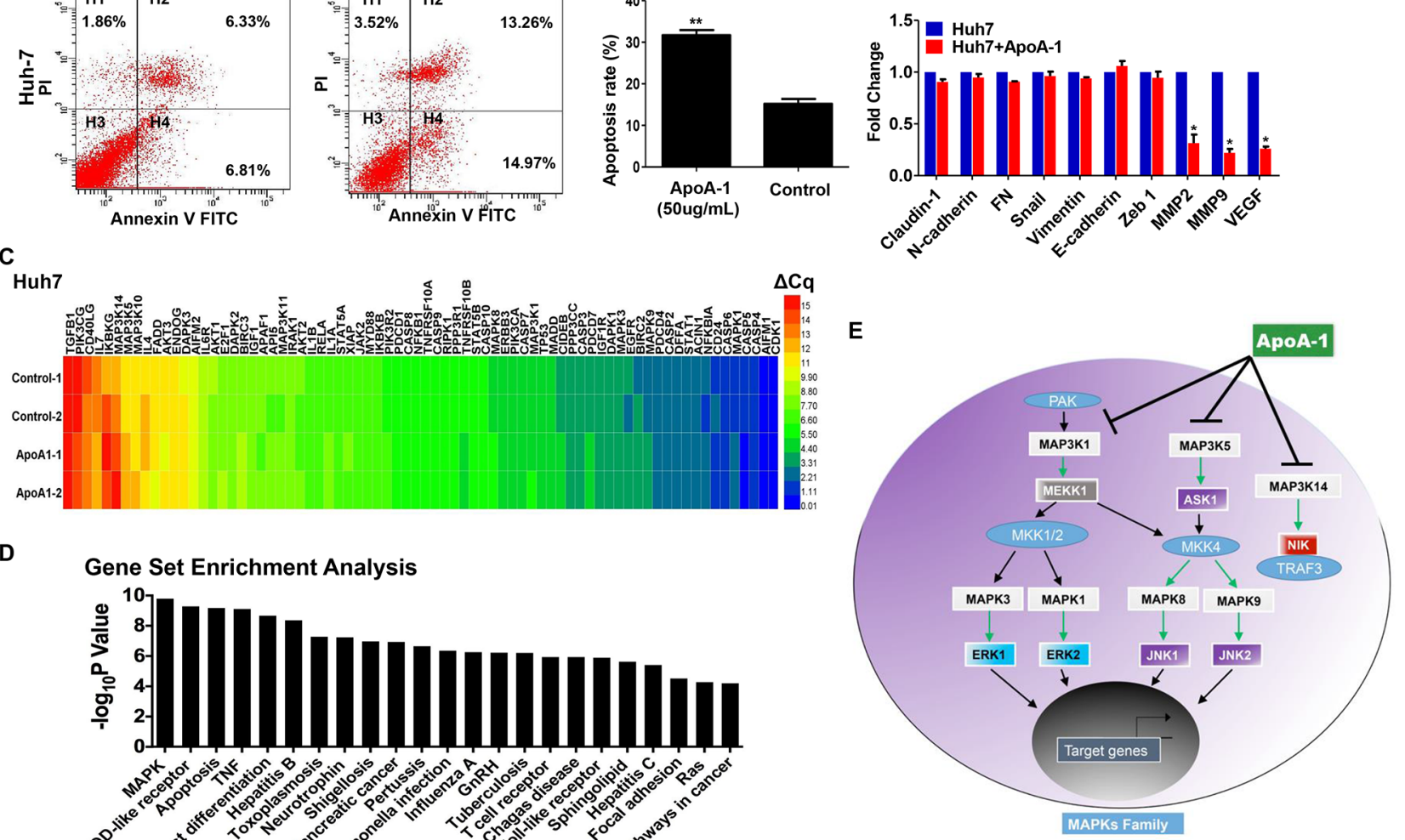

Figure 4: ApoA-1-induced apoptosis was associated with mitogen-activated protein kinase (MAPK) pathway. A. Apoptosis was detected by annexinV-FITC/propidiumiodide staining. In MHCC97H (up) and Huh7 (below) cells, the ApoA-1-induced apoptosis rates were higher than control group $\left(* P<0.05,{ }^{*} P<0.01\right)$. B. Relative expression of invasion-related genes after ApoA-1 treatment in MHCC97H (up) and Huh7 (below) cell lines. C. Heatmap of the results of PCR-array. D. Gene set enrichment analysis of altered genes involved in PCR array and results showed that MAPK signaling pathway was the most significant pathway affected by ApoA1 treatment. E. Potential mechanism underlying ApoA-1 inducing apoptosis. ApoA-1 treatment could decrease the expression of up-stream molecules as well as down-stream molecules in MAPK pathway, and thus greatly induces the apoptosis of HCC cells. 
nuclear factor Kappa-B kinase subunit Gamma (IKKG) were found to be notably reduced after ApoA-1 treatment (Figure 4C). Details were listed in Supplementary Table S2.

We further conducted the Gene Set Enrichment Analysis (GSEA) to figure out the signaling pathways significantly altered by ApoA-1treatment to investigate the mechanism underlying ApoA-1-induced-apoptosis. MAPK signaling pathway was identified to be the most significant pathway with the smallest $P$ value, and 9 of 14 altered genes were involved in this pathway (Figure 4D, Table 4). We further performed RT-PCR assay with different primers to determine the expression status of these 9 genes in Huh7 and $\mathrm{MHCC} 97 \mathrm{H}$, and the results were accordance with PCR-array data (Supplementary Figure S3).

\section{DISCUSSION}

ApoA-1, which is generally considered to protect against cardiovascular disease, has been reported to exhibit a unique effect on tumor progression in recent studies [12, $13,21,22]$. ApoA-1 was reported to be an early diagnosis marker in HCV-background HCC and low level of ApoA1 was correlated with formation of portal vein tumor thrombus as well as the progression of HCC. However, by far, no specific data about the correlation between ApoA1 level and TTR/OS was available and the prognostic value of serum ApoA-1 in HCC remained elusive [18, 19]. Our present study explored the clinical significance of serum ApoA-1 levels in HCC patients, and the potential mechanism mediated by ApoA-1 in tumor progression. We found that the serum ApoA-1 level was significantly lower in HCC patients with recurrent disease compared with patients without recurrence, and serum ApoA-1 was an independent predictor for recurrence and survival in HCC patients post-surgery in two independent cohorts. Considering the convenience of serum ApoA-1 analysis, there is potential for ApoA-1 to be used as a marker for tumor recurrence and treatment response surveillance. This may provide a powerful test, enabling accurate and early decision-making to tailor the most effective therapy according to the characteristics of individual tumors.

Hematogenous spread is an important cause of recurrence and metastasis in $\mathrm{HCC}$, and $\mathrm{CTC}$ in the bloodstream plays an important role in HCC metastasis $[23,24]$. A negative correlation was observed between the serum ApoA-1 level and the peripheral CTC level in $\mathrm{HCC}$ patients, and the recurrent rate of patients with high serum ApoA-1 levels was decreased significantly in HCC patients with detectable CTC. EMT is considered as a major mechanism involved in the dissemination of tumor cells in HCC [25], However, our current data showed that ApoA-1 treatment might inhibit CTC formation via EMT-independent mechanism, in which the expressions of MMP2, MMP9, and VEGF were strongly down-regulated (Figure 4B). These data suggested ApoA-1 might inhibit CTC formation via impairing extracellular matrix degradation properties of tumor cells and decreasing angiogenesis, which highlighted the potential mechanism of ApoA-1 in inhibiting tumor cells dissemination. Moreover, our vitro experiments implied that ApoA-1 could inhibit tumor cell proliferation and induce apoptosis. Of note, apoptosis-inducing function of ApoA-1 could be attributed to the inhibition of MAPK pathway, which plays a critical role in the carcinogenesis, maintenance and progression of HCC (Figure 4E) [20]. These results demonstrated the preliminary mechanism underlying the inhibition effect of ApoA-1 on HCC, which might provide a novel insight into anti-HCC research. Further systematical investigation focusing on the detailed mechanism of ApoA-1 in inactivating MAPK signaling is also undergoing in our lab.

Releasing of tumor cells into circulation is a multiple-step procedure, which including a great number of proteins, and ApoA-1 acts as one of the major molecules involved in this procedure, which could effectively affect the viability of CTCs. Based on our data, we believed that ApoA-1 was a significant negative regulator of CTC ( $p=0.013)$, though the correlation was a little bit weak $(\mathrm{r}=-0.235)$. Taken together, these findings indicated that ApoA-1 protein might decrease the CTC level by preventing CTC formation, affecting the survival, and inducing apoptosis of tumor cells in circulation, which resulted in higher recurrence rates and poor outcomes in HCC patients with low serum ApoA-1 levels. Therefore, improving the serum ApoA-1 level in HCC patients might be a promising therapeutic strategy to limit tumor recurrence and metastasis in HCC patients post-surgery.

In clinical practice, it is challenging to predict tumor relapse in low recurrence risk HCC subgroups. The present study is the first to show that preoperative serum ApoA-1 levels retain their prognostic value in those subgroups at risk for which conventional clinicopathological variables offer limited information predicting tumor recurrence. To date, AFP has been the most extensively used biomarker for diagnosis and surveillance in HCC patients [26-28]. However, it is difficult to monitor recurrence in the $30 \%-40 \%$ of HCC patients with low AFP levels [4, 28]. Here, we have also shown that determination of the preoperative serum ApoA-1 level is a promising and feasible tool for recurrence prediction in patients with a low AFP concentration. The predictive significance of the serum ApoA-1 level in those subgroups would be that clinicians could identify patients at high risk of recurrence and enable targeted rational adjuvant therapy post-surgery. Up to now, analysis of serum ApoA-1 levels has been performed as a routine clinical liver function test using commercially available kits. The detection of serum ApoA-1 levels can be easily standardized to provide accuracy and reproducibility, strengthening the practical value of this test in contributing information for early 
Table 4: Gene set enrichment analysis of PCR-array

\begin{tabular}{|c|c|c|c|c|}
\hline Pathway & $\begin{array}{c}\text { Gene } \\
\text { number }\end{array}$ & Genes & P value & Q value \\
\hline MAPK & 9 & $\begin{array}{c}\text { IKBKG, MAP3K14, MAPK9, MAP3K5, MAPK8, } \\
\text { MAPK1, IL1A, MAP3K1, MAPK3 }\end{array}$ & $1.64 \mathrm{E}-10$ & $2.34 \mathrm{E}-10$ \\
\hline NOD-like receptor & 7 & $\begin{array}{c}\text { IKBKG, MAPK9, MAPK8, MAPK1, MAPK3, } \\
\text { BIRC3, CASP5 }\end{array}$ & $5.24 \mathrm{E}-10$ & $2.49 \mathrm{E}-10$ \\
\hline Apoptosis & 10 & $\begin{array}{l}\text { IKBKG, MAP3K14, MAPK9, MAP3K5, MAPK8, } \\
\text { MAPK1, MAPK3, BIRC3, APAF1, TNFRSF10B }\end{array}$ & $6.76 \mathrm{E}-10$ & $3.85 \mathrm{E}-13$ \\
\hline TNF & 8 & $\begin{array}{c}\text { IKBKG, MAP3K14, MAPK9, MAP3K5, MAPK8, } \\
\text { MAPK1, MAPK3, BIRC3 }\end{array}$ & $7.83 \mathrm{E}-10$ & $1.49 \mathrm{E}-10$ \\
\hline Osteoclast differention & 7 & $\begin{array}{c}\text { IKBKG, MAP3K14, MAPK9, MAPK8, MAPK1, } \\
\text { IL1A, MAPK3 }\end{array}$ & $2.18 \mathrm{E}-09$ & $2.49 \mathrm{E}-08$ \\
\hline Hepatitis B & 7 & $\begin{array}{c}\text { IKBKG, MAPK9, MAPK8, MAPK1, MAP3K1, } \\
\text { MAPK3, APAF1 }\end{array}$ & 4.44E-09 & $4.22 \mathrm{E}-08$ \\
\hline Toxoplasmosis & 6 & $\begin{array}{l}\text { IKBKG, MAPK9, MAPK8, MAPK1, MAPK3, } \\
\text { BIRC3 }\end{array}$ & $5.35 \mathrm{E}-08$ & $4.22 \mathrm{E}-07$ \\
\hline Neurotrophin & 6 & $\begin{array}{c}\text { MAPK9, MAP3K5, MAPK8, MAPK1, MAP3K1, } \\
\text { MAPK3 }\end{array}$ & $5.92 \mathrm{E}-08$ & $4.22 \mathrm{E}-07$ \\
\hline Shigellosis & 5 & IKBKG, MAPK9, MAPK8, MAPK1, MAPK3 & $1.09 \mathrm{E}-07$ & $6.74 \mathrm{E}-07$ \\
\hline Pancreatic cancer & 5 & IKBKG, MAPK9, MAPK8, MAPK1, MAPK3 & $1.18 \mathrm{E}-07$ & $6.74 \mathrm{E}-07$ \\
\hline Pertussis & 5 & MAPK9, MAPK8, MAPK1, IL1A, MAPK3 & $2.26 \mathrm{E}-07$ & $1.17 \mathrm{E}-06$ \\
\hline Salmonella infection & 5 & MAPK9, MAPK8, MAPK1, IL1A, MAPK3 & $4.51 \mathrm{E}-07$ & $1.98 \mathrm{E}-06$ \\
\hline Influenza A & 6 & $\begin{array}{c}\text { MAPK9, MAPK8, MAPK1, IL1A, MAPK3, } \\
\text { TNFRSF10B }\end{array}$ & $5.62 \mathrm{E}-07$ & $2.21 \mathrm{E}-06$ \\
\hline GnRH & 5 & MAPK9, MAPK8, MAPK1, MAP3K1, MAPK3 & 5.99E-07 & $2.21 \mathrm{E}-06$ \\
\hline Tuberculosis & 6 & $\begin{array}{c}\text { MAPK9, MAPK8, MAPK1, IL1A, MAPK3, } \\
\text { APAF1 }\end{array}$ & $6.21 \mathrm{E}-07$ & $2.21 \mathrm{E}-06$ \\
\hline T cell receptor & 5 & IKBKG, MAP3K14, MAPK9, MAPK1, MAPK3 & $1.17 \mathrm{E}-06$ & $3.51 \mathrm{E}-06$ \\
\hline Chagas disease & 5 & IKBKG, MAPK9, MAPK8, MAPK1, MAPK3 & $1.17 \mathrm{E}-06$ & $3.51 \mathrm{E}-06$ \\
\hline Toll-like receptor & 5 & IKBKG, MAPK9, MAPK8, MAPK1, MAPK3 & $1.28 \mathrm{E}-06$ & $3.66 \mathrm{E}-06$ \\
\hline Sphingolipid & 5 & MAPK9, MAP3K5, MAPK8, MAPK1, MAPK3 & $2.38 \mathrm{E}-06$ & $6.17 \mathrm{E}-06$ \\
\hline Hepatitis C & 5 & IKBKG, MAPK9, MAPK8, MAPK1, MAPK3 & $3.96 \mathrm{E}-06$ & $9.81 \mathrm{E}-06$ \\
\hline Focal adhesion & 5 & MAPK9, MAPK8, MAPK1, MAPK3, BIRC3 & $3.05 \mathrm{E}-05$ & $5.79 \mathrm{E}-05$ \\
\hline Ras & 5 & IKBKG, MAPK9, MAPK8, MAPK1, MAPK3 & $5.34 \mathrm{E}-05$ & $8.70 \mathrm{E}-05$ \\
\hline Pathways in cancer & 6 & $\begin{array}{l}\text { IKBKG, MAPK9, MAPK8, MAPK1, MAPK3, } \\
\text { BIRC3 }\end{array}$ & $6.43 \mathrm{E}-05$ & 0.0001 \\
\hline
\end{tabular}

Abbreviations: MAPK, mitogen-activated protein kinase; TNF, tumor necrosis factor; IKBKG, I-Kappa-B Kinase Subunit Gamma; BIRC3, Baculoviral IAP Repeat Containing 3; CASP5, caspase 5; IL1A, interleukin 1 alpha

decision making regarding the most effective therapy for each HCC patient.

In this study, we enrolled an independent cohort of patients to validate the clinical utility of serum ApoA1 levels and found that the clinical characteristics of the training and validation cohorts were similar, which indicated the reliability and universality of our findings. However, there are still several limitations to the present study. In our study, some recognized factors, such as tumor size, AFP, and vascular invasion are not the independent risk factors for TTR and OS for HCC. It might due to relatively short follow-up time and small size 
of cohort. Furthermore, it also should be noted that most HCC patients in China have a hepatitis B virus-positive background. Hence, a large-cohort, multicenter, longterm study including patients from different background is needed to validate the prognostic significance of the serum ApoA-1 level, and this is currently undergoing in our center. In addition, a comprehensive investigation of the mechanism of action of ApoA-1 on HCC cells also needs to be performed.

To our knowledge, this is the first report to demonstrate the clinical significance of serum ApoA-1 levels for predicting the prognosis of HCC patients. Our data indicates that the serum ApoA-1 level can serve as a novel, independent predictor of TTR and OS for HCC patients undergoing resection. Moreover, continuous monitoring of the serum ApoA-1 levels in HCC patients might provide useful information for the management of HCC and facilitate the implementation of different treatment options. The role of ApoA-1 in inhibiting the proliferation of tumor cells, as well as promoting apoptosis of cancer cells during tumor cell hematogenous dissemination, are presumably responsible for the high recurrence rate and poor prognosis observed in $\mathrm{HCC}$ patients with a low serum ApoA-1 level. The low cost, easy determination and reproducibility of serum ApoA1 analysis make ApoA-1 a promising biomarker for assessing $\mathrm{HCC}$ prognosis in future clinical practice. Furthermore, improving the serum AopA-1 level in HCC patients might be a promising therapeutic strategy to reduce recurrence and metastasis for $\mathrm{HCC}$ patients undergoing resection.

\section{MATERIALS AND METHODS}

\section{Study design}

From January to July 2012, we recruited 224 patients with HCC who underwent curative resection at Zhongshan Hospital (Fudan University, Shanghai, China) as a training cohort. We next recruited a validation cohort of 219 patients with $\mathrm{HCC}$ who underwent resection from August 2012 to August 2013 (Table 1). From July 2010 to June 2011, 113 HCC patients undergoing curative resection were prospectively recruited and their previously reported CTC levels were analyzed [29]. HCC was defined according to the findings of imaging scans and biochemical assays, and diagnosis was confirmed by histopathology according to the criteria of the American Association for the Study of Liver Diseases guidelines. The stage of HCC was determined according to the BCLC guidelines [3]. Tumor differentiation was defined using the Edmondson grading system [30]. A blood sample (7.5 mL) used for CellSearch analysis was collected two days before resection as described in our previous report [29]. Ethical approval for the use of human subjects was obtained from the Research Ethics Committee of Zhongshan Hospital, and informed consent was obtained from each patient enrolled in the study.

\section{Follow-up and tumor recurrence}

Every 3 to 4 months following resection, patients were monitored for serum AFP levels, and abdomen ultrasonography and chest X-rays were performed as previously described [31]. Follow-up ended in February 2015. TTR was defined as the interval between surgery and any diagnosed intrahepatic or extrahepatic recurrence. OS was defined as the interval between the date of surgery and the date of death, or the interval between surgery and the last observation.

\section{Determination of the serum ApoA-1 level}

The serum ApoA-1 concentrations were determined by immunoturbidimetry, using Hitachi 7600 automated biochemistry analyzer and ApoA-1 assay kits (Diasys Diagnostic Inc., Holzheim, Germany) according to the manufacturer's protocol. Serum samples were collected two days before surgery, and stock at $-80^{\circ} \mathrm{C}$ until detection. The X-tile 3.6.1 software (Yale University, New Haven, CT, USA) was used to determine the cutoff value of the serum ApoA-1 level for predicting tumor recurrence in the training cohort [32]. The optimal cut-off value was determined based on ApoA-1 concentrations, outcomes and time interval. Results from X-Tile analysis revealed an optimal cutoff point for the serum ApoA-1 level at 1.04 $\mathrm{g} / \mathrm{L}$ in the training cohort (Supplementary Figure S1). Thus, patients were stratified into ApoA-1 high ( $>1.04$ $\mathrm{g} / \mathrm{L})$ or low $(\leq 1.04 \mathrm{~g} / \mathrm{L})$ groups for all subsequent analyses.

\section{Detection of CTC}

The CTC detection was performed using the CellSearch system as previously described [33]. In brief, the semiautomated CellSearch platform (Janssen Diagnostics) enriches the sample for cells expressing EpCAM with ferromagnetic beads. Afterwards, fluorescently labeled monoclonal antibodies specific for leukocyte (CD45) and cytokeratins are used to distinguish epithelial cells from leukocytes. The identification and enumeration of CTCs were performed with the use of the CellSpotter Analyzer, and the results were expressed as the number of cells per $7.5 \mathrm{~mL}$ of blood.

\section{Cell lines and reagents}

Two human HCC cell lines with different metastasis potential were used in this study. MHCC97H was obtained from our institute [34]. The Huh7 cell line was provided by the Cell Bank at the Institute of Biochemistry and Cell Biology, China Academy of Science (Shanghai, China). All cell lines were maintained in high-glucose Dulbecco's modified Eagle's medium (DMEM) supplemented with 
$10 \%$ heat-inactivated fetal bovine serum (FBS), 100 units/ $\mathrm{mL}$ penicillin, and $100 \mathrm{mg} / \mathrm{mL}$ streptomycin at $37^{\circ} \mathrm{C}$ in a humidified incubator under $5 \%$ carbon dioxide. The recombinant human ApoA-1 (rhApoA1, E. coli source, \#350-11, Peprotech, Connecticut, USA) was dissolved in phosphate-buffered saline to prepare a stock solution and was stored at $-4^{\circ} \mathrm{C}$.

\section{Cell proliferation and apoptosis assays}

Cell proliferation and apoptosis assays were performed as previously described [35] with slight modifications. All experiments were performed in triplicate.

For the proliferation assay, cells were aliquoted into a 96-well plate at $1000 / 100 \mu \mathrm{L}$ per well, incubated for 24 $\mathrm{h}$, and treated with different concentrations of recombinant ApoA-1 $(0,25$ or $50 \mathrm{ug} / \mathrm{mL})$ in $200 \mu \mathrm{L}$ DMEM containing $10 \%$ FBS. After $72 \mathrm{~h}$, the medium was replaced by complete medium containing different concentrations of ApoA-1. Cells were exposed to ApoA-1 for 7 days. At the indicated time points, $20 \mu \mathrm{L}$ of cell counting kit 8 (CCK-8) solution (Dojindo, Kamimashiki-gun, Kumamoto, Japan) was added to determine the number of viable cells in each well.

Cell apoptosis was analyzed by flow cytometry using annexin V-fluorescein isothiocyanate (FITC). Apoptosis Detection Kits (BD Biosciences, San Jose, CA, USA) were employed according to the manufacturer's protocol [35]. Briefly, cells were treated with $50 \mu \mathrm{g} / \mathrm{mL}$ ApoA-1 for $72 \mathrm{~h}$, then harvested and suspended in a binding buffer $(1 \times)$. Cells were similarly treated without ApoA-1 as a negative control. An aliquot of $100 \mu \mathrm{L}$ was incubated with $5 \mu$ Lannexin V-FITC and $5 \mu$ Lpropidium iodide for $15 \mathrm{~min}$ in the dark, and $400 \mu \mathrm{L}$ binding buffer $(1 \times)$ was added to each sample. The stained cells were analyzed by flow cytometry within $1 \mathrm{~h}$.

\section{RNA isolation, qRT-PCR and PCR array}

Total RNA was extracted from cell lines using RNeasy mini kit (Qiagen, Germany) according to the manufacturer's instructions. mRNA expression in HCC cell lines was measured by qRT-PCR using an LightCycle480 instrument (Roche Diagnostics, Germany). qRT-PCR was done using a LightCycle480 SYBR I Master Mix (Roche Diagnostics, Germany) according to the manufacturer's instructions. qRT-PCR was performed with an initial denaturation at $95^{\circ} \mathrm{C}$ for $5 \mathrm{~min}$ followed by 40 cycles of denaturation at $95^{\circ} \mathrm{C}$ for $15 \mathrm{~s}$, annealing and extension at $60^{\circ} \mathrm{C}$ for $30 \mathrm{~s}$. GAPDH was used as an internal control. The primers were listed in Supplementary Table S2. Relative mRNA levels were calculated based on the $\mathrm{Ct}$ values and normalized using GAPDH expression, according to the equation: $2-\Delta \mathrm{Ct}[\Delta \mathrm{Ct}=\mathrm{Ct}$ (Target) - $\mathrm{Ct}(\mathrm{GAPDH})]$. All experiments were done in triplicate. A human apoptosis PCR array (CT Bioscience, PAI) was used to analyze the expression of key genes participated in ApoA-1 induced apoptosis, according to the manufacturer's instructions [20]. In brief, Huh7 cells were harvested after treatment with $50 \mathrm{ng} / \mathrm{ml}$ ApoA-1 or ddH2O for 72 hours. Afterwards, total RNAs were extracted by Trizol regent (Lifetechnology, USA) and reverse transcripted into cDNA by Quntitect Reverse Transcription Kit (Qiagen, Germany).

\section{Statistical analysis}

Statistical analyses were performed using SPSS 20.0 software (IBM, Chicago, IL, USA). Experimental values for continuous variables were expressed as the mean \pm standard error of the mean. The chi-squared test, Fisher's exact probability tests and the Student's $t$-test were used as appropriate to evaluate the significance of differences in data between groups. If variances within groups were not homogeneous, the nonparametric MannWhitney test or the Wilcoxon signed-rank test was used. The relationships between serum ApoA-1 level and TTR and OS were analyzed using Kaplan-Meier survival curves and log-rank tests, respectively. Univariate and multivariate proportional analyses were performed using the Cox proportional hazard regression model and $\mathrm{p}<0.05$ was considered statistically significant.

\section{Abbreviations}

HCC, hepatocellular carcinoma; ApoA-1, Apolipoprotein A1; TTR, time to recurrence; OS, Overall survival; ROC, receiver operating characteristics; AFP, $\alpha$-fetoprotein; BCLC, Barcelona Clinic Liver Cancer; CTCs, circulating tumor cells; PCR, polymerase chain reaction.

\section{ACKNOWLEDGMENTS}

The authors thank the participating patients for the source of clinical blood samples.

\section{CONFLICTS OF INTEREST}

The authors declare no conflict of interest.

\section{GRANT SUPPORT}

This study was supported by grants from the National High Technology Research and Development Program (863 Program) of China (2015AA020401), the State Key Program of National Natural Science of China (81530077), the National Natural Science Foundation of China (81572064, 81372317, 81472676 and 81572823), the Projects from the Shanghai Science and Technology Commission (13140901900,134119a1201,14DZ1940300, 14411970200 and 14140902301), the Strategic Priority Research Program of the Chinese Academy of Sciences 
(XDA12010202), Specialized Research Fund for the Doctoral Program of Higher Education and Research Grants Council Earmarked Research Grants Joint Research Scheme (20130071140008) and the Open Fund of Key Laboratory of Carcinogenesis and Cancer Invasion, Fudan University, Ministry of Education (KLCCI2014-3).

\section{REFERENCES}

1. Torre LA, Bray F, Siegel RL, Ferlay J, Lortet-Tieulent J, and Jemal A. Global cancer statistics, 2012. CA Cancer J Clin. 2015;65:87-108. doi: 10.3322/caac.21262.

2. Ji J, Shi J, Budhu A, Yu Z, Forgues M, Roessler S, Ambs S, Chen Y, Meltzer PS, Croce CM, Qin LX, Man K, Lo $\mathrm{CM}$, et al. MicroRNA expression, survival, and response to interferon in liver cancer. N Engl J Med. 2009;361:1437-47. doi: 10.1056/NEJMoa0901282.

3. Bruix J, and Sherman M. Management of hepatocellular carcinoma: an update. Hepatology. 2011;53:1020-2. doi: 10.1002/hep.24199.

4. Forner A, Llovet JM, and Bruix J. Hepatocellular carcinoma. Lancet. 2012;379:1245-55. doi: 10.1016/ S0140-6736(11)61347-0.

5. Liu Z, Xiao Y, Tang L, Jiang L, Wang Y, Zhang R, Wei Q1, and Lu Y. Apolipoprotein A1-75 G/A and +83 C/T polymorphisms and renal cancer risk. Lipids Health Dis. 2015;14:143. doi: 10.1186/s12944-015-0132-0.

6. Das M, Wilson CJ, Mei X, Wales T, Engen JR, and Gursky O. Structural Stability and Local Dynamics in DiseaseCausing Mutants of Human ApolipoproteinA-I: What Makes the Protein Amyloidogenic? J MolBiol. 2015; S0022-2836(15)00625-7. doi: 10.1016/j.jmb.2015.10.029.

7. Libby P, Ridker PM, and Hansson GK. Progress and challenges in translating the biology of atherosclerosis. Nature. 2011;473:317-25. doi: 10.1038/nature10146.

8. Degoma EM, and Rader DJ. Novel HDL-directed pharmacotherapeutic strategies. Nat Rev Cardiol. 2011;8:266-77. doi: 10.1038/nrcardio.2010.200.

9. Camont L, Chapman MJ, and Kontush A. Biological activities of HDL subpopulations and their relevance to cardiovascular disease. Trends Mol Med. 2011;17:594-603. doi: 10.1016/j.molmed.2011.05.013.

10. Chammem H, Hafaid I, Bohli N, Garcia A, Meilhac O, Abdelghani A, and Mora L. A disposable electrochemical sensor based on protein $\mathrm{G}$ for High-Density Lipoprotein (HDL) detection. Talanta. 2015;144:466-73. doi: 10.1016/j. talanta.2015.06.009.

11. Kasumov T, Li L, Li M, Gulshan K, Kirwan JP, Liu X, Previs S, Willard B, Smith JD, and McCullough A. Ceramide as a mediator of non-alcoholic Fatty liver disease and associated atherosclerosis. PLoS One.2015;10:e0126910. doi: 10.1371/ journal.pone.0126910.

12. Gao F, Vasquez SX, Su F, Roberts S, Shah N, Grijalva V, Imaizumi S, Chattopadhyay A, Ganapathy E, Meriwether
D, Johnston B, Anantharamaiah GM, Navab M, et al. L-5F, an apolipoprotein A-I mimetic, inhibits tumor angiogenesis by suppressing VEGF/basic FGF signaling pathways. IntegrBiol (Camb). 2011;3:479-89. doi: 10.1039/ c0ib00147c.

13. Zamanian-Daryoush M, Lindner D, Tallant TC, Wang Z, Buffa J, Klipfell E, Parker Y, Hatala D, Parsons-Wingerter P, Rayman P, Yusufishaq MS, Fisher EA, Smith JD, et al. The cardioprotective protein apolipoprotein A1 promotes potent anti-tumorigenic effects. J BiolChem. 2013;288:21237-52. doi: 10.1074/jbc.M113.468967.

14. Chong PK, Lee H, Zhou J, Liu SC, Loh MC, So JB, Lim $\mathrm{KH}$, Yeoh KG, and Lim YP. Reduced plasma APOA1 level is associated with gastric tumor growth in MKN45 mouse xenograft model. J Proteomics. 2010;73:1632-40. doi: 10.1016/j.jprot.2010.04.005.

15. Tuft Stavnes H, Nymoen DA, HetlandFalkenthal TE, Kærn J, Tropé CG, and Davidson B. APOA1 mRNA expression in ovarian serous carcinoma effusions is a marker of longer survival. Am J ClinPathol. 2014;142:51-7. doi: 10.1309/ AJCPD8NBSHXRXQL7.

16. Guo X, Hao Y, Kamilijiang M, Hasimu A, Yuan J, Wu G, Reyimu H, Kadeer N, and Abudula A. Potential predictive plasma biomarkers for cervical cancer by 2D-DIGE proteomics and Ingenuity Pathway Analysis. Tumour Biol. 2015;36:1711-20. doi: 10.1007/s13277-014-2772-5.

17. Steel LF, Shumpert D, Trotter M, Seeholzer SH, Evans AA, London WT, Dwek R, and Block TM. A strategy for the comparative analysis of serum proteomes for the discovery of biomarkers for hepatocellular carcinoma. Proteomics. 2003;3:601-9.

18. Mustafa MG, Petersen JR, Ju H, Cicalese L, Snyder N, Haidacher SJ, Denner L, and Elferink C. Biomarker discovery for early detection of hepatocellular carcinoma in hepatitis C-infected patients. Mol Cell Proteomics. 2013;12:3640-52. doi: 10.1074/mcp.M113.031252.

19. Xu X, Wei X, Ling Q, Cheng J, Zhou B, Xie H, Zhou $\mathrm{L}$, and Zheng $\mathrm{S}$. Identification of two portal vein tumor thrombosis associated proteins in hepatocellular carcinoma: protein disulfide-isomerase A6 and apolipoprotein A-I. J Gastroenterol Hepatol. 2011;26:1787-94. doi: 10.1111/j.1440-1746.2011.06796.x.

20. Wang Y, Luo Z, Pan Y, Wang W, Zhou X, Jeong LS, Chu Y, Liu J, and Jia L. Targeting protein neddylation with an NEDD8-activating enzyme inhibitor MLN4924 induced apoptosis or senescence in human lymphoma cells. Cancer Biol Ther. 2015;16:420-9. doi: 10.1080/15384047.2014.1003003.

21. Gao F, Chattopadhyay A, NavabM, Grijalva V, Su F, Fogelman AM, Reddy ST, and Farias-Eisner R. Apolipoprotein A-I mimetic peptides inhibit expression and activity of hypoxiainducible factor- $1 \alpha$ in human ovarian cancer cell lines and a mouse ovarian cancer model. J Pharmacol Exp Ther. 2012;342:255-62. doi: 10.1124/jpet.112.191544. 
22. Su F, Kozak KR, Imaizumi S, Gao F, Amneus MW, Grijalva V, Ng C, Wagner A, Hough G, Farias-Eisner G, Anantharamaiah GM, Van Lenten BJ, Navab M, et al. Apolipoprotein A-I (apoA-I) and apoA-I mimetic peptides inhibit tumor development in a mouse model of ovarian cancer. Proc Natl Acad Sci U S A. 2010;107:19997-20002. doi: 10.1073/pnas.1009010107.

23. BarbuV, BonnandAM, Hillaire S, Coste T, Chazouilleres O, Gugenheim J, Boucher E, Poupon R, and Poupon RE. Circulating albumin messenger RNA in hepatocellular carcinoma: results of a multicenter prospective study. Hepatology.1997;26:1171-5.

24. Li J, Shi L, Zhang X, Sun B, Yang Y, Ge N, Liu H, Yang X, Chen L, Qian H, Wu M, and Yin Z. pERK/pAktphenotyping in circulating tumor cells as a biomarker for sorafenib efficacy in patients with advanced hepatocellular carcinoma. Oncotarget. 2016;7:2646-59. doi: 10.18632/ oncotarget.6104.

25. Yuan JH, Yang F, Wang F, Ma JZ, Guo YJ, Tao QF, Liu F, Pan W, Wang TT, Zhou CC, Wang SB, Wang YZ, Yang $\mathrm{Y}$, et al. A long noncoding RNA activated by TGF- $\beta$ promotes the invasion-metastasis cascade in hepatocellular carcinoma. Cancer Cell. 2014;25:666-81. doi: 10.1016/j. ccr.2014.03.010.

26. Sato Y, Nakata K, Kato Y, Shima M, Ishii N, Koji T, Taketa K, Endo Y, and Nagataki S. Early recognition of hepatocellular carcinoma based on altered profiles of alphafetoprotein. N Engl J Med.1993;328:1802-6.

27. Poté N, Cauchy F, Albuquerque M, Voitot H, Belghiti J, Castera L, Puy H, Bedossa P, and Paradis V. Performance of PIVKA-II for early hepatocellular carcinoma diagnosis and prediction of microvascular invasion. J Hepatol. 2015;62:848-54. doi: 10.1016/j.jhep.2014.11.005.

28. Johnson PJ. The role of serum alpha-fetoprotein estimation in the diagnosis and management of hepatocellular carcinoma. Clin Liver Dis. 2001;5:145-59.
29. Sun YF, Xu Y, Yang XR, Guo W, Zhang X, Qiu SJ, Shi RY, Hu B, Zhou J, and Fan J. Circulating stem cell-like epithelial cell adhesion molecule-positive tumor cells indicate poor prognosis of hepatocellular carcinoma after curative resection. Hepatology. 2013;57:1458-68. doi: 10.1002/hep. 26151 .

30. Wittekind C. [Pitfalls in the classification of liver tumors]. Pathologe. 2006;27:289-93.

31. Guo W, Yang XR, Sun YF, Shen MN, Ma XL, Wu J, Zhang CY, Zhou Y, Xu Y, Hu B, Zhang X, Zhou J, and Fan J. Clinical significance of EpCAM mRNA-positive circulating tumor cells in hepatocellular carcinoma by an optimized negative enrichment and qRT-PCR-based platform. Clin Cancer Res. 2014;20:4794-805. doi: 10.1158/1078-0432.CCR-14-0251.

32. Camp RL, Dolled-Filhart M, and Rimm DL. X-tile: a new bio-informatics tool for biomarker assessment and outcome-based cut-point optimization. Clin Cancer Res. 2004;10:7252-9.

33. Cristofanilli M, Budd GT, Ellis MJ, Stopeck A, Matera J, Miller MC, Reuben JM, Doyle GV, Allard WJ, Terstappen LW, and Hayes DF. Circulating tumor cells, disease progression, and survival in metastatic breast cancer. $\mathrm{N}$ Engl J Med. 2004;351:781-91.

34. Li Y, Tian B, Yang J, Zhao L, Wu X, Ye SL, Liu YK, and Tang ZY. Stepwise metastatic human hepatocellular carcinoma cell model system with multiple metastatic potentials established through consecutive in vivo selection and studies on metastatic characteristics. J Cancer Res ClinOncol. 2004;130:460-468.

35. Zhang X, Yang XR, Sun C, Hu B, Sun YF, Huang XW, Wang Z, He YF, Zeng HY, Qiu SJ, Cao Y Fan J, and Zhou J. Promyelocytic leukemia protein induces arsenic trioxide resistance through regulation of aldehyde dehydrogenase 3 family member A1 in hepatocellular carcinoma. Cancer Lett. 2015;366:112-22. doi: 10.1016/j.canlet.2015.06.014. 